\title{
Reimagining Professional Development for Digital Literacies: Old, New and Pandemic
}

\author{
SUZANNA WONG \\ University of Alberta \\ LINDA LAIDLAW \\ University of Alberta \\ YINA LIU \\ University of Alberta
}

\begin{abstract}
During the COVID-19 pandemic teachers have been expected to learn new digital literacy skills, often applying them immediately. While professional development structures within school districts and professional associations are organized to offer supports, teachers may be challenged to gain digital skills within existing professional development models. Within our study, teachers explored technologies with the aim of rethinking frames for teaching and learning literacy. Following the start of the COVID-19 pandemic they shared their experiences, insights and challenges. In our article, we address implications for digital literacy teaching and learning and the need for new ways of approaching teacher development.
\end{abstract}

Keywords

literacies, professional development, makerspace literacies, technologies

\section{Introduction}

Our paper examines one of the ways that the COVID-19 pandemic has impacted teachers' digital practices, presenting a snapshot of how professional development (PD) supports might respond to online teaching requirements. We (Suzanna and Linda) have been working with a group of teachers for the past five years, with Yina joining our research team as research assistant two years ago. While our original intention for the group was to look at teacher perspectives on digital change and curriculum practices for new and emerging technologies, one of the unintended insights was that, sparked by teacher comments, we also began to consider some of the existing structures for teacher professional learning and how learning about new technologies may (or may not) be addressed. As we have noted in our previous work as teachers, and as shared by the teachers in our focus group, some professional development endeavors and events can tend to be 'top down' and administration or professional association driven in many areas of education, with teachers as the intended recipients for knowledge, and structured as lecture series, classroom-instructional style sessions and so on. Teacher professional development approaches can tend to mirror models of teacher education and classroom instructional models (Martin \& Polly, 2016). In the province where we are situated, the Alberta 
Teachers' Association (ATA) organizes or supports many professional development activities for teachers that can be undertaken individually or collaboratively. For example, educators can participate in action research projects in their classrooms, join book study groups, organize classroom or school visitations, and take post-secondary courses or conferences and also receive some funding support for such activities (ATA, 2021). In addition, depending on school focus and particular literacy plans, PD related to specific literacy approaches or resources may also be required by particular schools or school districts. Teachers assigned to positions as literacy (or other subject area) consultants or coaches may also be charged with offering professional development supports.

The teacher research group that we address in this article was initially set up as an informal focus group to consider topics of digital literacy and curriculum reform. When we started the group, in the province of Alberta where were we were all located, the Ministry of Education was in the process of preparing for curriculum reforms, developing a new 'Programme of Studies' (Alberta's mandated curriculum). These reforms were intended to take up wider educational transformations and present new visions of education, with an increased emphasis on diversity, inclusion, Indigenous reconciliation, and developing more flexible learning structures to support creativity, innovation, and changing needs of $21^{\text {st }}$ century learners. In our initial planning for the focus group, we were responding to a need expressed by teachers we had previously been working with in graduate courses, that they would like to have opportunities to explore innovative ideas in a collective and interactive way. As we started our work with the teacher focus group, we initially discussed the emerging curriculum initiatives and shared documents focusing on classroom literacy practices. We provided a meeting space, resources and time for informal conversation and a meal together, as teachers were coming from busy days in the classroom, followed up by our focus group session. Often, however, the informal conversations shared examples and classroom experiences that later became a focus for problem-solving or pedagogical discussion, incorporated into our 'official' work in our sessions.

In our planning, we were informed by Sumara's (1996, see also Sumara, Davis \& van Der Wey, 1998) structuring of literary inquiry groups for teachers and students, where shared experiences of texts and practices are aimed at creating new insights and understandings. While our group did not typically work with literary texts, aside from several classroom picture book examples-we shared expository and popular media texts as well as digital materials within our meetings - one key aim for the group was a focus on resymbolizing and re-interpreting technology experiences in new ways.

Within the group, the teachers expressed that they preferred the informal and flexible structure of the meetings to more structured district professional development sessions, with some expressing that the focus group sessions filled a void they experienced after completing graduate studies, and they looked forward to the conversations that provided opportunities for critical reflection on pedagogical structures and practices. The following statement shares one of the teachers' responses to our meetings:

I am very glad to be part of this group because it is like a professional development workshop with no pressure. It is kind of like a show and tell, maybe more like club with a group of keen teachers from different schools. We like to piggyback on each other's ideas. I always leave this room with tons of new ideas for my class. 
The membership within this research project/literacy and technology "club" has been flexible, with teachers inviting colleagues, and with some teachers attending occasionally as life or work have intervened. A core group of 5 participants have consistently attended. The aims and practices within the group have also shifted according to the teachers' interests and the classroom or school challenges they were experiencing, as well as what we (Linda and Suzanna) were interested in studying in our own digital media research projects.

Over the past three years, based on interests and school contexts of participants as well as some of our own new research funding to support acquiring a small collection of materials and resources, we shifted towards a focus on "makerspace" activities that could bring together existing literacy practices, "maker" activities and some new ways of thinking about literacy and technology. The maker movement refers to an approach that embraces creative production by providing the technologies, resources, and materials to create texts and objects through experimentation and problem-solving (Halverson \& Sheridan, 2014; Peppler \& Bender, 2013). While makerspaces are not discipline specific, and have often been aligned with science inquiries, "making" as a literacy practice builds on a strong foundation of research focusing on materiality and the embodiment of meaning making (see e.g., Burnett, 2015; Rowsell, 2020).

In our newly funded project, we focused on working with teachers to engage in literacy work that is multimodal (i.e., using different resources, texts and media including digital and non-digital materials), exploring "making," "tinkering," "hacking," and producing different kinds of texts and objects and then reflecting upon possible student learning processes and thinking. Following Marsh et al. (2018), we have focused on "the ability to engage in critical reflection and problem-solving, and the ability to network" ( $p$. 50) in this work.

\section{The Teachers}

Within the group, participating teachers have diverse teaching backgrounds and experiences - teachers who are early career and those who are mid-career or later, with some who were working in early primary years classrooms as well as some teachers working in upper elementary or middle years. English language support teachers, literacy consultants and individuals who worked in administration were also part of the group, as well as a teacher who was focusing on homeschooling her three children who joined the group more recently. Teachers who attended the group were teaching in urban, suburban and rural communities, with some spending considerable commuting time to come to our group after a full day of school. Participating teachers had different comfort levels with technology use in their teaching practices; some had technology leadership roles, while others saw themselves as novices. Most of the participants have completed graduate degrees in Education, and some had previously taken graduate language and literacy courses from either Linda or Suzanna. Despite their diversity, the teacher participants have continued to share a number of common interests and goals. They are interested in educational innovation and reform, and finding ways to bring new ideas to their classrooms and schools and are keen to find ways to access and use digital technologies and take up "makerspace" ideas in literacy instruction. As the group has continued to meet over time, 
the conversations have often evolved into sharing new ideas, activities, projects and pedagogical approaches to teaching literacy in elementary schools.

\section{Coffee House Culture}

Our earlier discussion sessions as well as our makerspace focused sessions were informed by a coffee house culture or "salon" approach (Johnson, 2010a) to encourage idea sharing and generation. The historical roots of this approach can be traced to the $1600 \mathrm{~s}$, often where poets, writers and a range of intellectuals would meet to engage in "sober" exchanges (rather than the inebriated sort that would take place in pubs). We believed it was important to create structures (relational, technological, and pedagogical) where "ideas could mingle and swap" (Johnson, 2010b). Our format, which involved time for initial socializing and food, and unhurried opportunities to play with ideas as well as time to work with "maker" materials, such as robots (Dot and Dash), iPad applications, augmented reality tools, Lego and button making kits, as "focal activities". This structure allowed for teachers to share their own classroom stories and examples, as well as sharing of strategies (both successful ones and those connected to challenges) to flow and for the other teachers to make their own connections and contribute strategies and understandings in response. Most of our meetings, according to the teachers, resulted in them taking away new ideas, strategies and resources to use in planning for their own classrooms. Rather than being structured as more formalized professional development session structures, the makerspace sessions were informal, social and provided opportunities for exploration of materials by teachers and our research team. The sessions often involved laughter, active discussion and analysis, as well as events not always going as planned-we sometimes sorted through the same technical difficulties teachers experienced in classrooms, spending purposeful time to work out "the kinks" — as we explored new materials and strategies together.

\section{Pre-pandemic Exploration: Button Making}

A conversation erupts in a corner of our literacy lab space. Julia is describing her newest literacy makerspace gadget - a button maker which she has been using in her grade one classroom as a part of literacy centre activities. Suzanna is intrigued by what seems to be an "old fashioned" tool making its way back into classrooms.

Julia recounts, "We're making all kinds of buttons with cool messages and pictures on them. The kids love making their own buttons and then wearing the final products!" As the rest of the teacher group overhears the conversation, they quickly join in, asking questions about the possibilities of using a button maker as a technology tool in their own classrooms and considering how they might use it to support different literacy competencies at different grade levels.

The preceding conversation took place during one of the last series of 'in person' meetings for our group before the pandemic impacted our ability to get together. Julia's sharing of how she had used button-making sparked a larger exploration of this tool and the keen interest of the teachers led to the purchase from our research funds of buttonmaking tools for the group to use. As this vignette illuminates, the idea of using this "old" technology, with some "new" digital extensions caught the excitement of the teachers as 
an interesting literacy focused maker activity. As Julia shared, by using the button makers [see Figure 1] and an assortment of iPad drawing apps [see Figure 2], it was possible to mix old and new technologies together to create personalized buttons, and to develop a series of "making" activities that generated much excitement in her young students.
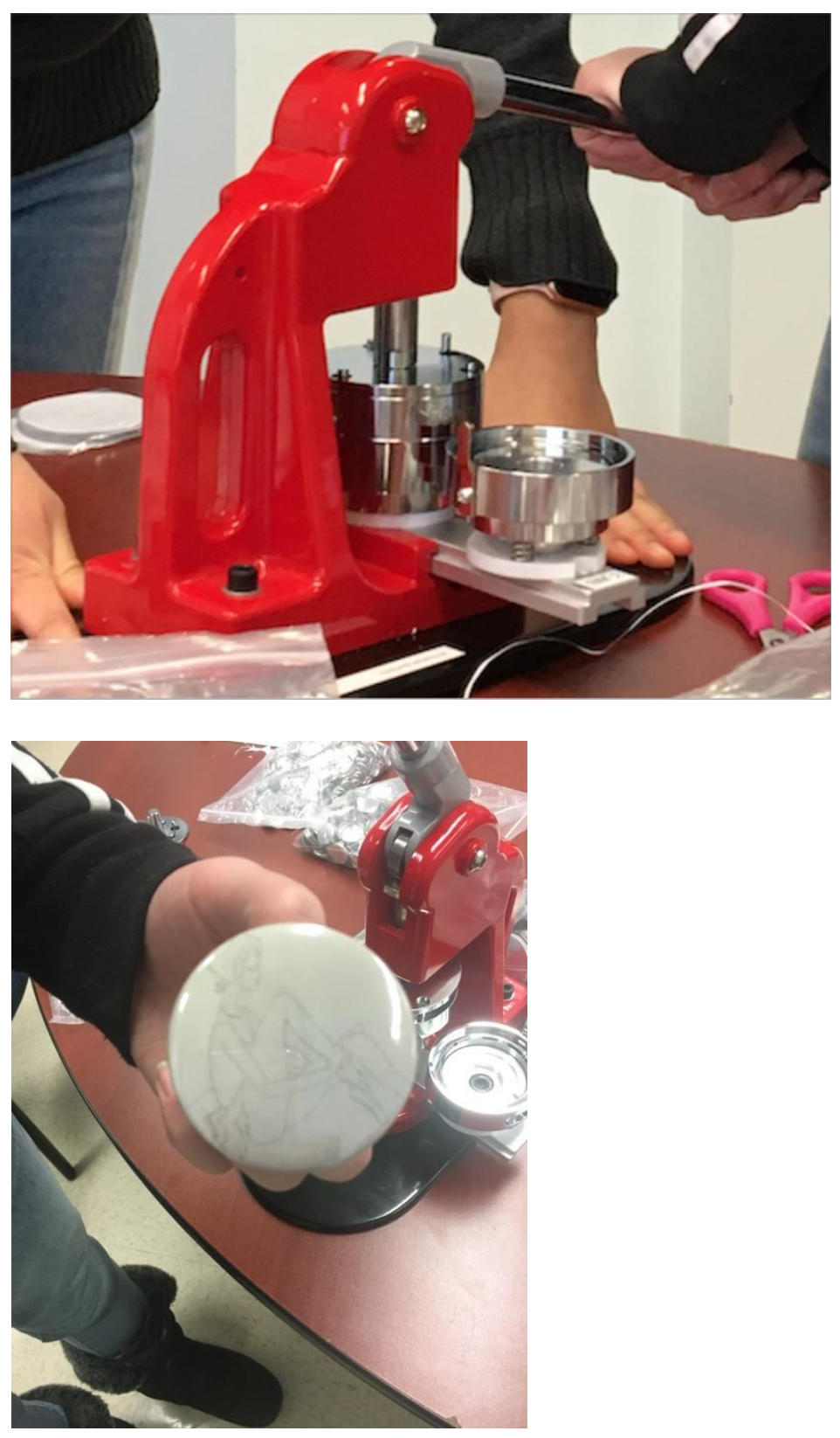

Figure 1. Making Buttons 


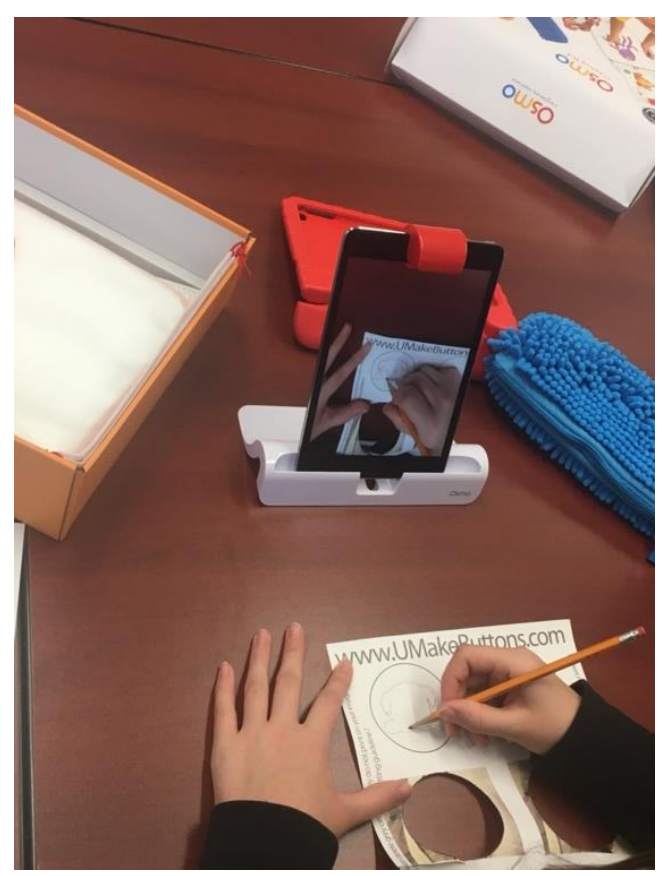

Figure 2. Designing Buttons with iPad Apps

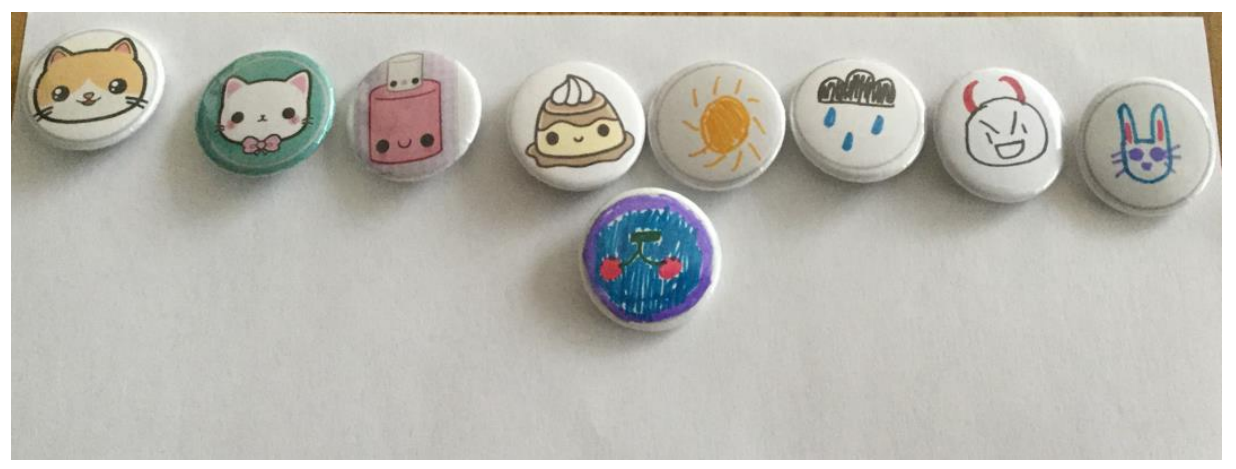

Figure 3. Buttons Made by Children

While buttons with messages on them are certainly not new - they have been used for years for advertising (political campaigns, charities, products), sold at rock concerts or developed to convey other aspects of pop culture - they are making a comeback among youth and have also been part of the DIY (do-it-yourself) maker movement. We are also seeing them returning as a trend in contemporary popular music, as K-Pop bands and their fans have popularized buttons connected to their music.

At one of the last sessions where we were able to meet in person, we created personalized buttons using crayons, markers and paper, downloaded online images, and some teachers created images using drawing apps on tablets or laptops. As we all engaged in button creation, we talked about how this activity might be used in the teachers' various classrooms and teaching contexts. Teachers shared diverse strategies for using them for early primary classrooms as well linking them to novel studies or advertising units for older 
elementary students, considering how button creation could be part of lessons focusing on meaning, design, images and critical thinking, looking at the communication and textual possibilities within the small spaces of buttons.

As the COVID-19 pandemic hit globally as well as in Canada and in our province, we just had set up our next meeting, keen to start a new 'take home' project, where teachers could borrow the button maker, robot kits, as well as other resources, to work with in their classrooms. We envisioned this as somewhat similar to take home/traveling stuffed animal initiatives that we and the teachers had enacted with our students, where students journaled and photographed the experiences of the "stuffie" in their home. Instead of a stuffed animal, the teachers would be documenting student experiences with the maker equipment to share with us and the other teachers, with the aim of developing some practical resources that might be shared with other teachers. But, in early 2020, most of our participants had to move their teaching online due to all local schools shutting down for the remainder of the school year (the only member who did not have to do so was the homeschooling parenther children continued on with their learning with some different adaptations connected to everyone in the family being at home all the time). Not so surprisingly, while we remained in communication with the teachers in our group through email, and Suzanna spoke to most participants via occasional phone calls, after shifting to full days of classroom video communication, teachers had little energy left to meet up remotely with our group.

While we had tentatively planned for a meeting in late winter, as restrictions seemed to be easing, unfortunately we are still waiting for a face-to-face gathering, at the time of our writing. Over the past year, the situation for classrooms has shifted multiple times and often with little warning - from "in person" instruction in Fall term with many restrictions (limited cohorts of children, masks required, attempts for as much social distancing as possible), to several weeks of online instruction in December for grades 7 12 , to district or school-based switches to online instruction when there were rising case counts and quarantines, to our current situation where all schools $\mathrm{K}-12$ have moved back to online instruction with an uncertain trajectory for the rest of the school year. As restrictions at the university and for in person gatherings have not allowed meetings in person, our group remains "on hiatus" for our usual group gatherings, and we have shifted to one-to-one communication, which the teachers have preferred as many have still wanted to touch base, but do not have the time for online group meetings. Our conversations with teachers have also shifted to considerations of digital professional development and the development of some new approaches to exploring makerspace strategies.

\section{Digital Professional Development-Pandemic PD}

Given the rapid and compulsory shifts to, from and back again to online teaching as a result of the pandemic, the teachers in our group as well as all of their peers have required supports for learning how to use what have been unfamiliar teaching platforms and technologies for some. Even for the teachers who were experienced technology users were being required to use different skills, as no one had taught groups of elementary aged children fully remotely before. In the early stages of the pandemic, when schools switched to online very suddenly, teachers did the best they could, often without much professional development support. The teachers in our group were primarily using the Google platforms that were used throughout the local school districts, but in the early days of the pandemic, 
districts had to sort out provision of laptops, access to $\mathrm{Wi}-\mathrm{Fi}$ and more, so immediate supports were focused on simply being able to provide some sort of instruction for all students. "Good enough" instruction was the aim, and teachers recounted that professional development supports were initially focused on ensuring that teachers and students could connect - in some cases with much less digital experience for students. In some regions, the teachers reported that photocopied workbooks were provided because of a lack of access to computers or internet. As the pandemic continued the teachers' school districts developed new ways of working to provide 'pandemic PD' which did not require in person meetings.

One of the teacher participants in our group (Jennifer) shared with us, in a combination of conversations and emailed interview questions, some insights she had about her role as a literacy consultant, where she was tasked with providing online professional development, for online literacy teaching:

We are not providing professional learning in person. We present and coach through pre-recorded videos and live virtual sessions. We are constantly creating resources and lesson plans for online teachers.

In her usual role, she would be visiting schools in person, and providing literacy "coaching" as well as offering district sessions that teachers from different schools might attend. During the pandemic, such events were not permitted in her region. As she noted further, the challenges for virtual PD have been quite different from those of in person work with teachers:

It is hard to "read the room" (some people keep cameras off). When dropping into discussions when teaching online, you can join breakout rooms to listen but it is not the same as walking by groups in person to provide that timely comment or feedback. We have shrunk our many of our sessions.... That has been lots of work for us, in additional to creating new interactive virtual processes for engagement. However, while she and other teachers in our group have experienced some challenges in the lack of "in person" professional learning supports, she and the other teachers also note that the convenience of being able to view or participate in sessions in their classrooms or at home without having to commute after a long day at school to get to a district session site. As well, other unexpected benefits have become clear, both in connection to virtual PD sessions and virtual "coaching" (the provision of one-to-one supports and feedback):

Teachers have preferred having digital rather than paper resources. Instead of receiving a bunch of paper handouts, it is helpful to have it saved on a platform they can regularly return to (Google Classroom or Site)... I have received lots of positive feedback about virtual coaching! Teachers feel isolated in their classrooms and this is a powerful way to feel supported and connected.

The teachers we have worked with have been too "screen fatigued" from so many of their work requirements being virtual and online between their own teaching and their district PD (sometimes required, especially as schools have experienced sudden shifts to remote/at home schooling) and extra work placed on them with classroom quarantines to have the energy to navigate yet one more virtual meeting with our group. As well, they have all reported having to juggle more uncertainty in their own schools this year in addition to their own worries about health and life in a pandemic. However, we have been interested 
to see how some of the practices we have experienced as successful for digital learning seem to be emerging in positive ways in the teachers' schools. Jennifer reflected,

I think seeing technology being used helps teachers envision how they can use it.... The learning curve was small for some and drastic for others. I was impressed at the growth and perseverance of teachers who call themselves "technologically challenged".

As we have experienced in our teacher research group, and also in our own teaching, hands on opportunities to explore technologies, "make things" and witness others engaging in digital practices often seems to benefit all across our groups with less experienced teachers trying out new devices and strategies, and adding their own innovations, and with experienced digital users supporting those who are less experienced. Within our teacher focus group we typically have worked with a mix of digital and nondigital maker activities, with everyone able to access the strategies that fit best for their own teaching and their students' needs - as illustrated by the button maker events. Jennifer suggests that this mix of what she calls "high tech" and "low tech" was also important for the teachers she was supporting and her own online teaching:

There are benefits to low tech versus high tech teaching online. Teachers fell on a continuum based on the teachers' skills and students' skills. Last year, I used Google Meet [video conferencing platform] with Kindergartens but I did not get them to do Google docs [word processing platform]. We did low tech, writing on paper and holding it up to the screen. With my grade 3 intervention students, we did more high tech, building words with Whizzimo [digital reading/spelling app] and creating Jamboards [interactive whiteboard system] to brainstorm ideas. The student's age and tech skills matter when planning. Not everything needs to be tech based.

We would echo Jennifer's perspective for teacher professional learning as well.

\section{Post Pandemic: What Then?}

As Jennifer admitted as she wrapped up our interview,

Teaching online is not for everyone. Even technologically savvy people (like myself) still prefer (and will always prefer) in person teaching. Teaching online is not the same as in person.

Similarly, pandemic online/virtual professional development has been for the most part a necessity rather than a preference, for the teachers in our group. Yet, we see some possible post-pandemic benefits that may, provide some scaffolds for both student instruction and teacher professional learning, as well as for our own focus group going forward. As Jennifer shared, even the most "technologically challenged" teachers have gained some new digital skills. New approaches to online instruction and virtual communication may support a reimagining of digital literacy practices, perhaps incorporating innovative strategies for students to interact with one another and collaborate, as both teachers and students have gained more confidence and expertise with the digital platforms that can be used.

As we have heard from the teachers in our focus group, they have all gained new strategies, ideas and learned new ways of working with digital applications - both the "low tech" and "high tech" strategies Jennifer points to. We know that not all teachers have the 
time and energy right now to be critically examining the pedagogical implications of various digital strategies - in the middle of the pandemic, they have had a lot to deal with, and many teachers have been in "survival mode". But we are hopeful that when we emerge from the pandemic, the collective and shared experiences with online teaching, use of virtual platforms and various digital applications and tools will provide opportunities for reflection, critique and considerations that will be valuable for the future of literacy teaching and learning.

As we begin to make plans for our teacher focus group, we know that everyone is looking forward to the time when we can meet in person again. Everyone has stories to share about their experiences with online teaching and attempts to continue "making" when students were at home or teachers had to consider restricted COVID-prevention rules in the classroom. We are hoping to restart our "take home maker kits". With professional development shifting in most school districts to virtual, online, and, in some situations, more personalized supports, we anticipate that we may see some shifts away from the "old" top-down practices that teachers reported were happening in their schools and districts, in the past. The context of the pandemic has meant that teachers needed to gain new digital skills very quickly, which also required systems to change rapidly. While in the past, prior to the pandemic, teachers reported attending digital professional development sessions that did not meet their needs due to lack of access to "hands on" experiences, or inadequate use of equipment (in some schools teachers were not permitted to take tablets home to learn how to use new apps), or where school policies simply got in the way (devices locked away so that students and teachers could not access them), some barriers have "magically" disappeared when the need has been urgent. We hope that some of this open-ness will continue on.

As we contemplate the unpredictable future and our work with professional learning for our teacher focus group, we also wonder, once the pressures of "online-all-thetime" for teachers begin to ease, what our group will want to explore, and whether or not their virtual PD experiences in their schools will impact our work together going forward. Will they still prefer to meet after dinner and conversation? Or, will they prefer a virtual "salon" now that they have experienced virtual PD possibilities and not having to rush away from their classrooms? Will we develop some new hybrid structures with a combination of in person group meetings and virtual/online sharing? We know that when our group reconnects in whatever form our makerspace "coffee house" might be, that we will need to make time and space for listening, sharing, making, and problem-solving. We'll probably need to dust off the button-maker and see where that might lead.

\section{References}

Alberta Teachers' Association. (2021). PD activities for professional growth. Alberta Teachers' Association. https://bit.ly/3bxbV3h

Burnett, C. (2015). (Im)materializing literacies. In J. Rowsell \& K. Pahl (Eds.), The Routledge handbook of literacy studies (pp. 520-531). Routledge.

Halverson, E. R., \& Sheridan, K. M. (2014). The Maker Movement in Education. Harvard Educational Review, 84(4), 495-504.

Johnson, S. (2001). Emergence: The connected lives of ants, brains, cities, and software. Scribner. 
Johnson, S. (2010a). Where good ideas come from: The natural history of innovation. Riverhead Books.

Johnson, S. (2010b). Where good ideas come from. [Video]. TED. https://www.ted.com/talks/steven_johnson_where_good_ideas_come_from?langu age $=$ en

Marsh, J., Arnseth, H. C., \& Kumpulainen, K. (2018). Maker literacies and maker citizenship in the MakEY (Makerspaces in the Early Years) project. Multimodal Technologies and Interaction, 2(3), 50.

Martin, C., \& Polly, D. (Eds.). (2016). Handbook of research on teacher education and professional development. IGI Global.

Mason, M. (2009). Making educational development and change sustainable: Insights from complexity theory. International Journal of Educational Development, 29(2), 117-124.

OECD (2018). The future of education and skills education 2030: The future we want. Secretary-General of the OECD. https://www.oecd.org/education/2030/E2030\%20Position\%20Paper\%20(05.04.20 18).pdf

Peppler, K., Halverson, E., \& Kafai, Y. (Eds.). (2016). Makeology: Makerspaces as learning environments (Vols. 1-2). Routledge.

Rowsell, J. (2020). Making: Materializing affect through maker literacies. In K. Paul \& J. Rowsell (Eds.), Living literacies: Literacy for social change (pp. 137-161). The MIT Press.

Sumara, D. (1996). Private readings in public: Schooling the literary imagination. Peter Lang.

Sumara, D. Davis, B., \& van der Wey, D. (1998). The pleasure of thinking. Language Arts, 76(2), 135-143. http://www.jstor.org/stable/41484086

Author Biographies

Suzanna So Har Wong is a former early childhood educator now working as an Adjunct Professor and Assistant Lecturer in Language and Literacy Education, at the University of Alberta. Her research focuses on young children's literacy practices at home and in school. Her current research project, A longitudinal study of children's multiliteracy practices in 'out-of-school' settings focuses on children's literacy engagements in- and out-of-school environments and examines children's perspectives on these literacy practices. ORCID ID: 0000-0001-6473-9603

Linda Laidlaw is a Professor working in the area of early literacy in Language and Literacy Education at the University of Alberta. Formerly a classroom teacher, her research focuses on digital and mobile technologies in primary education, diversity, and the relationships between children's digital practices at home and their experiences at school. Her latest projects, funded by the Social Sciences and Humanities Research Council of Canada, working with teachers, parents and children, investigates new pedagogical frames and strategies for literacy education in a changing world. ORCID ID: 0000-0002-2017-4302 
Yina Liu is a PhD student in Language and Literacy, at University of Alberta. She is interested in culturally and linguistically diverse children's digital literacy at home in her doctoral research. She completed her MEd program in 2017, exploring how Canadian children's literature could help newcomer children to transit better into Canada. 